\title{
Engaging Students in Error Analysis and Correction: A learner-Centered Approach to Improving Linguistic Accuracy
}

\author{
Evariste Manirakiza* and Innocent Hakizimana
}

Centre for Language Enhancement, University of Rwanda, Rwanda

\author{
ARTICLE INFO \\ Keywords: \\ Error analysis \\ language accuracy \\ learner-centered approach
}

\begin{abstract}
Students frequently commit errors despite spending huge amount of time studying language. This paper discusses a classroom-based teaching inquiry about error analysis and correction. The study focused on the use of simple past in paragraphs. The objectives of the investigation were to understand the extent to which dealing with students' errors in a leaner-centered classroom improves accuracy in English and to assess students' attitudes to the approach in language learning. The inquiry involved 62 first-year students from the College of Agriculture, Animal Sciences and Veterinary Medicine at the University of Rwanda. Individual and group work, a questionnaire and class observations were data collection tools. Findings revealed that the majority of students significantly improved their writing as a result of analyzing their errors in written work. In addition, students reported that correcting errors together gave them confidence and freedom to explore their language use more freely, to discuss their errors, to learn new words in their field of study, and to avoid repeating error while writing. Class observations showed that students were discussing and listening to each other's opinions attentively and critically. The researchers concluded that students acquire more language accuracy when they are deeply involved in error analysis as they feel motivated and responsible for their own learning.
\end{abstract}

\section{Introduction}

Language accuracy is of paramount importance in communication. Students are engaged in different academic and social contexts where they have to express their ideas and opinions using language. Students express themselves more effectively when they have a good grasp of grammar. In this regard, Agbesi (2016) stated that learning how words are combined in sentence formation enables language speakers to communicate effectively. One of the ways to enhance language accuracy is to deal with it in the classroom context where most language learning sessions take place.

English is a second language in Rwanda. From 1996 to 2008 the language policy required the first three years of schooling be taught in Kinyarwanda, after which the students chose English or French as the primary language of instruction. University students were expected to perform equally well regardless of their linguistic choice (McGreal, 2008 cited in Tabaro, 2015). However, the linguistic reforms of 2008 which took place in Rwanda required the shift from French into English as the sole language of instruction from primary four onwards. From 2008, students were expected to be accurate enough in English to communicate academically and professionally at the end of their studies. Talking about the importance of the language knowledge, Sasan (2012) highlighted that accuracy is an important factor to effective writing.

* Corresponding Author E-Mail Address: manirakizaeva91@ gmail.com 
Similarly, Celce-Murcia 1991; Schmidt 1994; Shaw \& Liu (1998) cited in Sasan (2012) mentioned that learning grammatical structures is important if it is designed to meet educational and professional goals.

\subsection{Context}

English has been a medium of instruction in Rwanda at different levels of education since 2008. Other languages which are used are Kinyarwanda as a mother tongue, which is used in all settings, and French. Whereas English is used as a medium of instruction, French is taught as a subject at secondary level and as an optional course at university. The Center for Language Enhancement of the University of Rwanda, College of Arts and Social Sciences teaches English for Specific Purposes and English for Academic Purposes as crosscutting modules respectively in the first and second years undergraduate. Though English is taught to university students, Kinyarwanda remains the language of communication out of the classroom.

Despite many years of English language study in Rwanda, students still make many errors especially those related to the use of tenses even at university level. For example, some students can confuse the simple past with the past perfect; others can just use the simple past instead of using the past perfect. Others can use the simple present instead of using the simple future. Some others can use the passive rather than the active forms of tenses. This situation leads to confusion and misunderstanding as it impedes communication among students, academic success and subsequently professional achievement. Therefore, there is a need to devise ways for tenses to be more accurately internalized. The purpose of the present study was to examine whether a learner-centered approach to error analysis and correction could help students at the University of Rwanda increase their level of mastery of tenses in English. In the inquiry we wanted to know whether students' involvement in error correction and analysis can help students make fewer errors in the use of tenses and hence improve their accuracy in using English.

Research studies were carried out on errors in language teaching and learning. For example, Rotim (2015) carried out a study on Learners' Attitudes towards Error Correction in English as Foreign Language (EFL) writing and found out that students had a positive attitude towards error correction. He also found that learners learn from their errors and hence prevent reoccurrence of errors in writing. Additionally, Lee 2004 cited in Rotim (2015) found out that learners expect to be corrected and believe that correcting errors is essential in language enhancement. Although many studies about error correction have been done, research concerning students' errors in a learner-centered context is still limited. Thus, the purpose of this inquiry was to investigate into the role of error analysis and correction in the improvement of language accuracy in a learner-centered context. Two research questions guided the inquiry. The first concerned the extent to which dealing with students' errors in a leaner-centered classroom improved accuracy in English especially in the use of tenses. The second was to examine students' attitude to a learner-centered approach to learning English.

\subsection{Class-Based Teaching Inquiry}

In the teaching context, an inquiry is defined as "a complex process that encompasses many different dimensions including fostering inquisitiveness (a habit of mind) and providing teaching strategies for motivating learning" (Minstrell \& Zee cited in Bodzin and Beerer, 2003, p. 3). Focusing on science subjects, Bidzin and Beerer (2003, p. 40-41) states that

"Inquiry teaching requires that students combine processes as they use scientific knowledge reasoning and critical thinking to develop their understanding of science. Engaging students in activities of and discussions about scientific inquiry help them develop and understanding of scientific concept...; skills necessary to become 
independent inquiry about the natural world and the dispositions to use the skills, abilities and attitudes associated with science."

According to Dawson (2017), teacher inquiry has been serving as a support for teachers in studying their own practice. Similarly, teacher inquiry is believed to make easier the focus on learners within specific contexts (Cochran-Smith \& Lytle, 2009; Darling-Hammond, Hammerness, Grossman, Rust, \& Shulman, 2005 cited in Athanases et al. 2012). "Teacher inquiry is grounded in perspectives on learning through action and reflection (Dewey, 1934, 2005 cited in Athanase, 2012, p. 5). Teacher inquiry begins in "problems and contexts of practice... and in the ways practitioners collaboratively theorize, study, and act on those problems in the best interests of the learning of students" (Cochran-Smith \& Lytle, p. 123 cited in Athanases, 2012, p. 5). In the light of these views, we wanted to know the extent to which engaging students in error analysis and correction could help them to acquire accuracy and hence reduce the occurrence of errors in English. We had a belief that the data could help reflect on the way teachers use to deal with students' errors. As teachers conduct inquiry, tools and the data they generate can prompt reflection on teaching and learning (Athanases, 2013).

\subsection{Importance of Error Analysis and Correction}

Error correction is important in language teaching and learning. In this regard, errors inform teachers about students' progress so that they can plan their lessons accordingly. As Corder (1973) cited in Khansir and Pakdel (2018) stated, with errors, the teacher is informed about how his/her teaching materials and techniques have been effective, what has been mastered as well as what needs emphasis in future lessons. Likewise, students' errors indicate the language learning process and should therefore be looked at thoroughly (Ringbom, 1987 cited in Wu, 2014).

Understanding the concepts of error correction and feedback are essential for language learning. Johnson (1999) cited in Khansir and Pakdel (2018) states that 'error correction is a form of feedback'. He makes a distinction between error correction and feedback. He adds that with the feedback the teacher provides information to support his students to come to the use of the language.

\subsection{Learner-Centered Approaches to Error Analysis and Correction}

Error analysis and correction in second language learning can be student-centered. In this regard, Rotim (2015) highlights the importance of learners' self- correction in a language classroom. He discusses how peer correction and self-correction can be used to successfully promote students' practice in writing. Similarly, the students' knowledge on how to do peer correction and self-correction could reduce their dependence on the teacher Rotim (2015) 1994:65). Therefore, engaging students in the analysis of errors instills in them the sense of responsibility and self-dependence. In addition, giving more responsibilities to students allows to have much time to practice their lessons Khansir (2010) cited in Pakdel (2018) while correcting errors.

\section{Materials and Methods}

The present Classroom-Based Teaching Inquiry (CBTI) was designed to examine whether involving students in error analysis and correction helps them reduce the number of errors they make. We also intended to know students' views after using the approach.

\subsection{Study Population and Sample}

This project was conducted in a class of 62 first year students studying English for Specific Purposes in the department of Animal Production and Veterinary Medicine, in the College of 
Agriculture, Animal Sciences and Veterinary Medicine of the University of Rwanda. It was expected that everyone in the class (75 students) would participate in the study but only 62 were present in class during the research period.

\subsection{Data Collection Tools and Procedures}

\subsubsection{Evaluation}

We asked each student to write two paragraphs on their motivation to enter their fields of study and their expectations in the future. We went through the papers to know which tense has the most frequent occurrence of errors among the present simple, the present perfect, the past simple, the past perfect and the future before students started analysing their errors. To do this we looked at whether each paper had no errors, one error, two errors, and three errors and more involving the use of the tenses. We asked students to write other paragraphs on the same topic two weeks after the error analysis and correction session. The aim of the activity was to see whether students could write better paragraphs, with fewer or no errors involving the use of simple past which was the tense with the most frequent occurrence of errors in their previous papers. To do this in an objective way, we identified papers with no errors; one error; two errors and those with three errors and more involving the use of the simple past and we compared the percentages with those in the previous papers.

\subsubsection{The Questionnaire}

After the last submission of students' paragraphs, we gave a questionnaire to students to get their views about the approach used. The questions in the questionnaire looked at difference aspects of the research inquiry. The first question was about whether there was improvement in terms of using the simple past between the first and the second time they wrote their paragraphs. The second question was about respondents' views on writing their paragraphs the second time. The fourth question was to ask respondents whether the way they had analysed and corrected the errors in small groups had been helpful. The fourth was whether the lesson devised on the target structure was useful. The last question was asking respondents whether they wished to continue to work on errors in the same way. For each of the questions respondents had to provide the reasons for their answers. The questions are given below.

Question 1: Do you think you improved in the use of the simple when you wrote your paragraphs the second time? Why or why not?

Question 2: How did you feel while writing the paragraphs the second time?

Question 3: Was the way you corrected the errors in small groups helpful? Why or why not?

Question 4: Was the lesson we did about the grammar point useful? Why or why not?

Question 5: Would you like to continue with to work on errors in the same way in the future?

\subsubsection{Teacher Observations}

Students were asked to write a-two paragraph paper about their motivation to enter the domain of Animal Production and Veterinary Medicine. Then, we collected their papers and went through them, identifying sentences having errors with tenses. To do this, charts to highlight common errors were devised. In the second-class session, we asked students to analyse errors in the sentences in groups of five and correct them. While students were working, we observed what they were doing and took notes on what we saw. We were interested in seeing whether they were participating more than in previous classes, how they were discussing errors and whether and how they were challenging one another.

After the group work, we called students together for a whole class analysis and discussion. During the exercise, we noticed that there were errors that students had not managed to correct on their own during the group analysis. So, we designed a grammar lesson to explain more about on the use of the simple past. During the grammar lesson we explained different uses of 
the simple past. The focus was on the aspects which were difficult for students to correct while doing the analysis. After that we gave them exercises to help them internalize the notion.

\subsection{Data Analysis}

The study involved both qualitative and quantitative data. Quantitative data were on the frequency of errors in students' papers in the two sessions. Qualitative data was on students' opinions and class observations. We considered common opinions and grouped them in themes. These were in turn also quantified. We compared these findings to our observations, frequency of errors in students' papers and their views.

\section{Results}

The following tables present different types of errors found in students' papers, results from student's evaluations, observations and students' views from the questionnaire.

\subsection{Occurrence of students' errors in their papers}

Table one shows different types of tense errors associated made by students during the inquiry, namely those related to the simple present, the present perfect, the past simple and the past perfect.

Table 1.

Occurrence of students' errors

\begin{tabular}{ccccccccccc}
\hline \multirow{2}{*}{ Tenses } & \multicolumn{2}{c}{ No errors } & \multicolumn{2}{c}{ One error } & \multicolumn{2}{c}{ Two errors } & \multicolumn{2}{c}{$\begin{array}{c}\text { Three errors and } \\
\text { more }\end{array}$} & Total \\
\hline & Students & $\%$ & Students & $\%$ & Students & $\%$ & Students & $\%$ & Students & $\%$ \\
\hline Simple present & 43 & 69.4 & 13 & 21 & 5 & 8.1 & 1 & 1.6 & 62 & 100 \\
Present perfect & 55 & 88.7 & 4 & 6.5 & 3 & 4.8 & 0 & 0 & 62 & 100 \\
Simple past & 11 & 17.7 & 17 & 27.4 & 18 & 29 & 16 & 26 & 62 & 100 \\
Past perfect & 54 & 87.1 & 6 & 9.7 & 2 & 3.2 & 0 & 0 & 62 & 100 \\
Future & 45 & 72.6 & 10 & 16.1 & 4 & 6.5 & 3 & 4.8 & 62 & 100 \\
\hline
\end{tabular}

Source: Class inquiry, April 2018

Table 1 displays different types of tense errors identified in students' papers in the first session of the inquiry. First of all, 69.4\% (43/62) of the students did not make any errors that involved the use of simple present and $21 \%$ (13/62) made one error. Still with the same tense, $8.1 \%$ $(5 / 62)$ made two errors while $1.6 \%$ (1/62) committed three errors and more. In addition, $88.7 \%$ $(55 / 62)$ made no errors regarding the use of the present perfect and 6.5\% (4/62) made one error. In the same way, $4.8 \%$ (3/62) made two errors and none made three and more errors involving the use of the same tense. Furthermore, 17.7\% (11/62) made no errors involving the use of the past simple while $27.4 \%$ (17/62) made one error. With the same tense, 29\% (18/62) made two errors while 26\% (16/62) made three errors and more. Also, 87.1\% (54/62) made no errors involving the use of the past perfect; 9.7\% (6/62) made one error and 3.2\% (2/62) made two errors. None made three errors and more with the use of the past perfect tense. Finally, $72.6 \%$ $(45 / 62)$ of the students made no errors involving the use of the future and $9.7 \%(6 / 62)$ made one error. With the same tense, 3.2\% (2/62) made two errors while 4.8\% (3/62) made three errors and more. Compare to the use of tenses, errors with most frequent occurrence were those related to the simple past. Therefore, the simple past was the target structure to focus on in the following sessions.

\subsection{Improvement in The Use of The Simple Past}

Table 2 displays the results on how students improved in the use of the simple past. It shows the numbers and percentages of students who made no errors, one error, two errors and three errors and more involving the use of the simple past both prior to the class and after two weeks. 
Table 2.

Improvement in the use of the simple past

\begin{tabular}{lcccc}
\hline \multirow{2}{*}{ Frequencies of Errors } & \multicolumn{2}{c}{ During class } & \multicolumn{2}{c}{ Two weeks after class } \\
\cline { 2 - 5 } & Students & Percentages & Students & Percentages \\
\hline No errors & 11 & 17.7 & 36 & 64.5 \\
One error & 17 & 27.4 & 14 & 22.6 \\
Two errors & 18 & 29 & 7 & 11.3 \\
Three errors and more & 16 & 25.9 & 1 & 1.6 \\
Total & 62 & 100 & 62 & 100 \\
\hline
\end{tabular}

Source: Class inquiry, April 2018

Table 2 shows the results on how students improved in the use of the simple past. As displayed in the table, the improvement is seen in all aspects of error occurrence with the use of the simple past examined in the students' papers. In this regard, the majority of students improved in the use of the simple past because the percentage of students with no errors in their papers increased from $17.7 \%(11 / 62)$ to $64.5 \%(36 / 62)$. Additionally, the percentage of students who made one error fell from $27.4 \%$ (17/62) to $22.6 \%$ (14/62). Furthermore, those who made two errors went down from $29 \%$ (18/62) to $11.3 \%$ (7/62). Lastly, the percentage of students who made three errors and more decreased from $25.9 \%(16 / 62)$ to $1.6 \%$ (1/62). In brief the table indicates that a large number of students improved in the use of the simple past in the second evaluation when they were asked to rewrite about their motivation to enter the field of Animal Production and Veterinary Medicine. Though there were students who still had few errors in their papers, the data suggests that the approach did help many students in the class. The fact that students generally improved in the use of the simple past was associated with the analysis they did together and the explanations provided during the grammar lesson.

\subsection{Views on How Peer Analysis and Correction of Errors Helped to Improve in The Use of} The Simple Past

Table 3 summarises the results of the students' questionnaires. It exhibits the data about students' views on how peer analysis and correction of errors helped them to rewrite their papers.

Table 3.

Students' views on how peer analysis and correction of errors helped rewriting

\begin{tabular}{lcc}
\hline & $\begin{array}{c}\text { Number of } \\
\text { students }\end{array}$ & $\begin{array}{c}\text { Percentage } \\
(\%)\end{array}$ \\
\hline Students report feeling free and confident while writing & 47 & 75.8 \\
Student report being very attentive to avoid mistakes & 7 & 11.3 \\
Students report lacking expressions & 3 & 4.8 \\
Students report not being interested in errors analysis with peers & 4 & 6.5 \\
No answers & 1 & 1.6 \\
Total & 62 & 100 \\
\hline
\end{tabular}

Source: Class Inquiry, April 2018

Table 3 shows the results from a questionnaire students filled out after they rewrote their paragraphs and evaluated how error analysis and correction helped them. As it is displayed, $75.8 \%$ (47/62) of students mentioned they were free and confident while rewriting. This matches the results from our observations. In fact, during error analysis students appeared to be practicing many language skills. For example, they asked each other about the meanings of words, sentence structure, as well as about tenses. From this exchange of knowledge, they managed to use the appropriate words for the context. These may have instilled in them more confidence when rewriting their paragraphs. Being very attentive to avoid mistakes was a common response among $11.3 \%$ (7/62) of students. A lack of interest in writing was attested 
by $6.5 \%$ (4/62) of students. Finally, $4.8 \%$ (3/62) said they did not have expressions while one student did not provide any answer to the statement. In a word, the error analysis session allowed students to gain enough skills for them to rewrite their papers more confidently.

\subsection{Usefulness of The Grammar Lesson}

Table 4 provides the summary of the results of the students' questionnaires. It presents the data about students' views on whether the grammar lesson was useful. The lesson was devised to strengthen the simple past because errors with this tense were the most common.

\section{Table 4.}

Whether the grammar lesson was useful

\begin{tabular}{lcc}
\hline & Number of students & Percentage \\
\hline Students report finding the lesson useful & 59 & 95.2 \\
Students report finding the lesson not useful & 3 & 4.8 \\
Total & 62 & 100 \\
\hline
\end{tabular}

Source: Class Inquiry, April 2018

Table 4 , shows that $95.2 \%$ (59/62) of the students agreed that the lesson was useful. Only $4.8 \%$ (3/62) did not. Students' reasons for why they thought the grammar lesson was helpful are displayed in the next sub-section.

\subsection{Reasons Why the Grammar Lesson Useful}

Table 5 displays the summary of the results of the students' questionnaires. It shows the data about students' views on the reasons why the grammar lesson was useful. It is necessary to remind that during the lesson, we provided more explanations on the use of the simple past. After the explanations we gave students exercises to write with the correct tense.

Table 5.

Students' reasons why the grammar lesson useful

\begin{tabular}{lcc}
\hline & $\begin{array}{c}\text { Number of } \\
\text { respondents }\end{array}$ & Percentage \\
\hline Students report having known how to use the simple past & 32 & 54.2 \\
Chance to know other skills & 11 & 18.6 \\
A support with more explanations & 9 & 15.3 \\
Providing ideas to each other & 1 & 1.7 \\
Writing meaningful sentences & 1 & 1.7 \\
No answer & 5 & 8.5 \\
Total & 59 & $100 \%$ \\
\hline
\end{tabular}

Source: Class Inquiry, April 2018

Table 5 shows that $54.2 \%(32 / 59)$ of the students said that the devised lesson helped them know how to use the simple past. In addition, 18.6\% (11/59) of students believed that the lesson helped them to practice other skills. Furthermore, $15.3 \%$ (9/59) of students mentioned that the additional explanations were useful. 1.7\% (2/59) of students said the lesson helped them to share; the same percentage of students said the lesson helped them write meaningful sentences. Five students did not provide any reasons for liking the lesson. In the same way, the 3 students who said the lesson was not useful as indicated in table 4 did not give any reason.

\subsection{Usefulness of Error Analysis and Correction}

Table 6 presents the summary of the results from the questionnaire in which students expressed their views on whether the error analysis and correction session were useful. 
Table 6.

Students' views on whether the error analysis session was useful

\begin{tabular}{lcc}
\hline & $\begin{array}{c}\text { Number of } \\
\text { students }\end{array}$ & Percentages \\
\hline Students report finding error analysis and correction useful & 59 & 95.2 \\
Students report finding error analysis and correction not useful & 2 & 3.2 \\
No answer & 1 & 1.6 \\
Total & 62 & 100 \\
\hline
\end{tabular}

Source: Class Inquiry, April 2018

According to Table 6, $95.2 \%(59 / 62)$ of the students felt that the error correction session was helpful. Two students said it was not useful while one student did not answer the question. Reasons why error analysis and correction was useful are provided in table 7.

\subsection{Reasons Why Error Analysis and Correction Was Useful}

Table 7 displays the results from the questionnaire in which students provided reasons why the error analysis and correction session was useful.

Table 7.

Reasons why students felt that error analysis was useful

\begin{tabular}{|c|c|c|}
\hline & $\begin{array}{c}\text { Frequencies } \\
\text { (n) }\end{array}$ & $\begin{array}{c}\text { Percentages } \\
(\%)\end{array}$ \\
\hline Students report having got chance to discuss about errors with colleagues & 50 & 84.7 \\
\hline Students report having learned new words in the field & 7 & 11.9 \\
\hline Students report having felt committed and united & 2 & 3.4 \\
\hline Total & 59 & 100 \\
\hline
\end{tabular}

Source: Class Inquiry, April 2018

Table 7 shows that 59 out of 62 students who said the error analysis and correction session was useful $84.7 \%$ (50/59) said they liked having a chance to discuss errors with colleagues. 11.9\% (7 out of 59) said that learning new words in the field while analyzing errors was helpful. 3.4\% (2/59) stated that they liked the sense of commitment and unity they felt as they analysed errors. The 2 students who reported that the error analysis and correction was not useful as shown in table 6 said that they did not like people correcting them.

\subsection{Desire to Do Peer Error Correction}

Students expressed their views on whether they wanted to continue with the same approach while dealing with errors in their English classes.

Table 8.

Students' desire to do error analysis and correction

\begin{tabular}{lcc}
\hline & Number of students & Percentage \\
\hline Students report having desire to do error correction & 55 & 88.7 \\
Students report not having desire to do error correction & 6 & 9.7 \\
No answer & 1 & 1.6 \\
Total & 62 & 100 \\
\hline
\end{tabular}

Source: Class Inquiry, April 2018

Table 8 shows that $88.7 \%$ (55/62) of students wanted to continue with the same activities. The table also indicates that $9.7 \%$ (6/62) did not want to do the activities again. One student did not to provide any answer. Reasons why students wanted to continue with error analysis and correction are provided in table 9. 


\subsection{Students' Reasons Why They Wanted to Do Peer Error Analysis and Correction}

Table 9.

Reasons why students wanted to continue with error correction

\begin{tabular}{lcc}
\hline & Number of students & Percentage \\
\hline Improving knowledge in English skills & 23 & 42 \\
Awareness and correction of errors & 24 & 44 \\
Avoiding errors while writing & 3 & 5 \\
Getting correction from the teacher & 4 & 7 \\
No answer & 1 & 1.8 \\
Total & 55 & 100 \\
\hline
\end{tabular}

Source: Class Inquiry, April 2018

Table 9 shows that 42\% (23/55) of the students liked improving their English skills with colleagues. $44 \%(24 / 55)$ said that they liked error correction because it helped them be aware of errors and correct them. 5\% (3/55) mentioned that avoiding errors while rewriting was helpful. 7\% (4/55) said that teacher was useful. One respondent did not answer.

Six students who did not like error analysis as displayed in table 8 gave different reasons. Two students said they prefer to correct themselves immediately after writing. One student asserted that dealing with errors in class is a waste of time and it is shameful. Another student mentioned that it took much time to correct errors of different opinions from the group. Another student said s/he needs to work on error slowly on an individual pace. The last student viewed errors in a negative way and did not want to continue in a wrong way. This might be because these students were not familiar with the approach and found it strange to them.

\subsection{Teacher Observations}

During the inquiry we observed students as they were discussing and analysing errors. We found that students were discussing the errors and correcting them in a collaborative way to get much skill. As we moved around, we could hear that they were trying to come to consensus about each error and how to correct it. As each and every one had a copy of sentences with errors, they had to agree on errors to correct and how to do it before they could move from one sentence to the next. This shows that peer error analysis and correction allow students to learn from their colleagues and promote collaborative language learning.

Our observations support students' data. In fact, the majority of students $(84.7 \%)$ reported that analysing errors helped them to discuss mistakes with colleagues. Some others indicated that they could learn new words in the field and feel commitment and united. This is evident because we found that they were working collaboratively. As students were discussing errors in collaboration, they managed to know how to use the simple past and write papers with few errors associated with the tense.

\section{Discussion}

\subsection{Improvement in use of the simple past}

A comparison of the number of errors in pre- and post-class evaluations showed that there was an improvement in the use of the simple past. Students reported that the error analysis and correction helped them use the simple past correctly. There were several reasons why they felt they improved in the correct use of the simple past. One student said 'I have improved because I have corrected my errors'. Another one stated, 'At the first time I made some errors but at the second time I tried to minimize them'. This is consistent with (Erdoğan, 2005)'s observation that the process of committing errors can be stopped by noticing them and working on them. In our study, students corrected their errors after a thorough analysis in groups, sharing views and discussing other language aspects. 
Class observations indicated that while analyzing and correcting errors, students collaborated and could learn more about the simple past. This is evident because one student said, 'at first I had some mistakes with the tense but after the correction I believe that I have improved'. Another one said, 'I learnt a lot about the simple past and this helped me the second time'. Another student mentioned, 'there are some mistakes I made the first time but after getting information about the simple past, I corrected and there is improvement'. This finding is consistent with views from various scholars who supported the importance of peer learning in acquiring language skills. In this regard, Fernández (2014) carried out a study on 'Vocabulary learning in collaborative tasks: A comparison of pair and small group work' and found out that students gain a lot of knowledge and linguistics resources while they are in small groups. In addition, Routman (2003) cited in Hurts et al. (2013) indicates that students increase their understanding when they are interacting with others. Almasi and Gambrell (1997) cited in Hurts (2013, p. 152) indicates that "participation in peer discussions improves students' ability to monitor their understanding of text, to verbalize their thoughts, to consider alternative perspectives, and to assume responsibility for their own learning". Brown (2001) cited in Kasim (2015) states that students feel self-confident and motivated when they are in groups. He also indicates that that students explore many opportunities to use the language when they are working together. In the same way, (Richards, 2005; Swain, 1995; Ellis, 1994 cited in Alfares, 2017) consider interaction as an essential part in language learning since it provides an opportunity for students to negotiate meaning. Therefore, engaging students in groups for a language activity is extremely useful in language learning.

\subsection{Valuing the Grammar Lesson}

Findings of the inquiry revealed that virtually all respondents considered the grammar lesson useful. Obviously, they found it useful because it came to fill the gap they had in terms of using the simple past. In fact, they encountered some difficulties while analysing and correcting the errors and could not find any way to overcome them on their own. The lesson was an intervention to provide supplementary explanations. Several reasons were given with regard to the importance of the grammar lesson. Most students mentioned that after the lesson they managed to write with the correct tense. One student said, 'the lesson was useful because it taught me how to use the simple past'. Another one said, 'the lesson helped us to know different ways of using the correct tense and to reduce grammatical mistakes'. Another one said, 'we worked and shared ideas on how to use the simple past together'. This means that the lesson shed light on what they did not manage to understand during error analysis and correction. This finding is supported by the view of Yaccob and Yunus (2019) and (Alijanian, 2012). They highlight the role of grammar and mention that it cannot be neglected as it is an important language structure for students to produce sentences which have a meaning. Gladys and Daphnée, (2010) carried out a study on 'Grammar Teaching and Learning in L2' and found out that much importance is given to language accuracy as it is a useful tool for speaking and writing very well. The role of grammar in language learning was also emphasized on by Navaz and Sama (2017). They carried out a study on 'Teaching Grammar in the English Language Classroom'and found out that grammar is a cornerstone in enhancing reading, writing and listening skills. In the same way, Pazaver and Wang (2009) cited in Navaz and Sama (2017) conducted a study on 'the impact of explicit instruction of grammar teaching among the foreign students in a Canadian university' and indicate that respondents, who were non-native speakers of English, were interested in learning grammar and believed it was very essential for a person in learning a new language. 


\subsection{Valuing Error Analysis and Correction Session}

Almost all students stated error analysis and correction was useful. The most common reason is that error analysis and correction was a supreme chance to discuss errors with their fellow students. As they indicated, they managed to go over the errors in their groups during the activity. Evidently, they shared knowledge and experience while correcting the errors. Most students mentioned that working in groups enabled them to identify errors, share ideas, listen to one another and feel united and committed. One student mentioned, "when we are in small groups, we work together in order to correct errors.' Another one mentioned, 'when we were discussing in groups, one came with ideas encouraging another. So, we felt united and committed.' Another one stated, 'We shared all possible ideas about the errors and we tried to correct them.' Another one stated, 'everyone was free to identify the errors; hence, easy learning'. This finding is supported by Al-Hoorie' view cited in Khansir and Pakdel (2018) on the benefit students get when they are working together. He states, "peer correction helps in thinking about the language when two learners are actively engaged in deciding on the best form of the language; listening to others' ideas helps in testing one's own knowledge" (Khansir and Pakdel 2018, p. 195 citing Al-Hoorie, 2017). Indeed, Rotim (2015) citing Saito (1994) highlights that with learners' awareness of the importance of peer correction and selfcorrection, learners can deal with error correction independently.

Several researchers highlighted the importance of error correction. In this regard, Faze et al. (2016) \& (Katayama 2007) \& (Jang 2003) \& (Gladys and Daphnée, 2010) indicate that students had a positive attitude towards error correction. Additionally, error correction has been valued by various scholars in different decades. In fact, Fitzsimmons \& Loomed, 1978; Heron, Kyree; Miller, 1991; Horn, 1947; Kyree, Heron, \& Goddard, 1997; Wirt et al., 1996 cited in Jill (2017) consider error as a very important instructional tool to acquire spelling. Similarly, Hedgcock; Lefkowitz 1994; F. Hyland 1998; Ferris \& Roberts 2001; Lee 2004 cited in Rotim (2015) found out that learners' expectation is to be corrected and their belief is that correcting errors is essential in language enhancement. Majority of students expected their teachers to correct their errors (Volcan and Yeúim, 2011) and have feeling of disappointment when they ignore them (Azar and Molavi, 2013 cited in Fawzi, 2016) and think that they have no mistake Sopin (2015). Likewise, findings from Katayama's study indicate that students viewed error correction positively because it fostered accuracy improvement in English language (Katayama, 2007 cited in Papangkorna, 2015).

Error correction as indicated by aforementioned authors appears as one-dimension process in which everything has to be done by language teachers. This being the case, error correction becomes a hindrance to language learning (Maicusi et al. 2000 cited in Rotin, 2015) and make learners anxious and should be avoided (Krashen, 1982 as cited in Zhu, 2010). Contrarily to the apparent one-way dimension of error correction, our findings revealed that having language learners involved in errors committed in their works, analysing and correcting them can be of great importance as many students in this study viewed their involvement as a golden tool in the learning process. Once students analyse their errors and proceed to correction themselves, language learning becomes enjoyable and increases their confidence. This corroborates the assertion of Rotim (2015). For him, students' practice in writing is promoted by peer correction and self-correction. The prominence of students' independence in learning was also observed in speaking. In this regard, cooperative learning lessens students' anxiety, increases their motivation and allows them to get rid of the problems they encounter while speaking (Leong and Ahmad, 2017). Similarly, interaction with others and learning from them was proved to be one way to enhance speaking skills (Prieto, 2007 cited in Leong and Ahmad, 2017).

From our findings we can say that students' motivation and interaction increased as they were sharing knowledge on error analysis and correction. In this regard, students' assertions indicate that they found the approach fruitful. Talking about students' motivation in language learning, 
Al-Hoorie's states that "motivation, in turn, is a function of integrativeness, attitudes toward the learning situation, and instrumentality" (Ali- Hoorie, 2017, p. 2). Similarly, Hurts et al. (2013) carried out a study on 'The Impact of Social Interaction on Student Learning' and found out that social interaction improves working environment and allows students to think critically and solve problems. They also indicated that social interaction is strongly correlated to students' learning. Similarly, "students learn more when they are able to talk to one another and be actively involved" (Routman, 2005 cited in Hurst et al. 2013). Similarly, while interacting students their language skills become greater as they listen to information provided by their fellows (Rivers, 1987 cited in Choudhury, 2005). In the same way, Vacca et al. (2011) cited in Hurst et al. 2013) state that learners' social interactions make them engaged. This is consistent with Dewey's view which states that knowledge is formed and owned by the learner when s/he is actively involved in the learning process (Dewey, 1963 cited in Hurst et al., 2013); hence, we can suggest that error analysis and correction by students in language classrooms be a frequent practice for they get engaged and motivated.

\subsection{Students' Desire to Continue with Error Correction}

The majority of respondents expressed their wish to go on with error analysis and correction. This is because the activity was enjoyable. Students gave different reasons they wish to continue with the same procedure. They stated that error analysis and correction helped them to improve their English skills and made them aware of their errors before correction. One student said, 'working on errors like that gives us a wide range of possible errors; therefore, the more we learn to correct errors together, the less we make them individually.' Additionally, our class observation showed that students were focused, working in groups and discussing. This corroborates the finding of Damon, 1984; and Bejarano, 1987 cited in Alfares (2017). They indicate that in group interactions students address any disagreements, receive feedback from each other and accept corrections. In the same way, Brown (2001) cited in Kasim (2015) states that students working in groups get much security and no criticism and insults; it helps those who were not able to naturally engage in learning activities. By the same token, Erdoğan (2005) carried out a study on 'Contribution of Error Analysis to Foreign Language Teaching' and realised that errors are of great importance to teachers and therefore recommended that teachers should adopt suitable teaching techniques in their classes. In our context, we opted for error analysis and correction by students themselves to allow effective language learning.

Papangkorna carried out a study on 'Students' Attitude and Preference Toward Error Corrections' and came up with a different finding. His study revealed that students wanted their teacher, rather than their fellows, to provide feedbacks on errors (Papangkorna, 2015). This might be because spoken errors were part of his study and his students felt they could not feel comfortable enough after their classmates' correction. Normally errors are unavoidable in language learning. However, students can feel embarrassed when they commit errors in front of their fellows and wish this would not happen anymore (Erdoğan, 2005). This is different from our situation in which student were dealing with written errors. During the analysis, they were discussing and they felt comfortable to talk to colleagues they knew very well. For this reason, the majority of them found the language learning approach appropriate. This is consistent with Nunan (1991)'s suggestion cited in Choudhury (2005) that learners' engagement in group interaction facilitates learning to speak. Similarly, Harmer (1991) cited in Choudhury (2005) states that group reactions can lead to discussions. This corroborates Kasim's finding. He conducted a study on 'Classroom Interaction in the English Department Speaking Class and found out that students' freedom to express themselves allowed them to talk a lot. He adds that such a case started when students were asked to engage in group discussion (Kasim, 2004). 
As indicated by the findings, students knew their errors and corrected them. This is because they had been talking to fellows in groups and none was afraid of talking to others. As a result, they managed to rewrite with a lot of attention, producing papers with fewer errors with the simple past. Indeed, this was proved by class observations made. In fact, students were working attentively in groups, discussing and listening to each other. This shows that they accorded great importance to working in groups. This finding matches with Lasagabaster and Doiz (2016) study on students' preferences on instructional preferences, where they found out that students were in favour of group work. From our study, it was observed that having analysed errors with their colleagues inspired students to correct and produce papers with fewer errors in the simple past. This confirms the finding of Hurts et al. (2013) which indicates that learning from each other increases students' ability to understand and remember.

\section{Conclusion}

There has been a debate among scholars on whether correcting errors has to be given room in language learning. Some said error correction may hinder students' performance while others believe that it helps them to get better performance when treated effectively. The present inquiry was seeking to know whether error correction in a learner-centered approach could improve accuracy in English language. In the inquiry, it was proved that error analysis and correction carried out by students is a very important aspect in language learning process. Contrary to the situation in which the language teacher is the one to provide correction to all the students' errors, the learner-centered approach proved to be more effective. In the inquiry students had many errors in the use of the simple past. After students have been put in groups to analyse and correct their errors, they got chance to discuss them and come to the same understanding. When they were asked to rewrite their paragraph, many of them managed to improve on the use of the simple past. As they reported, they felt free and confident as they were analyzing errors with their fellows. Finally, the majority of students had desire to do error analysis and correction in other class sessions. However, some few students reported they did not desire to work on errors in the same way, some saying that the approach could be done individually and others stating that it is a waste of time. Nonetheless, we believe that error analysis and correction remain fruitful as reported by the majority of students. Therefore, we suggest that involving students in error analysis and correction should be frequently used an effective approach in language teaching and learning especially in ESL (English as a Second Language) classes.

We suggest that the learner-centered approach be applied to correcting language errors. Students not only learn more about the language but also learn about themselves, listening to each other and sharing knowledge. While discussing, students analyse the nature of their errors and remind each other the language notions that they may have forgotten. In addition, there is no single doubt that dealing with errors in this way allows students to practice the speaking skill, and learn other language aspects when they discuss in the target language. In a word, engaging students in analyzing and correcting their errors is of a paramount importance and can be applied in a language classroom. Professional practitioners in language teaching should make use of this approach as it has proved effective. Future class enquiries should look at the effectiveness of students' involvement in enhancing the acquisition of writing skills and teachers' reflection on students' errors.

\section{Acknowledgements}

Firstly, we would like to express our sincere gratitude to Dr Anne Marie Kagwesage, the director for the Centre for Language Enhancement at University of Rwanda. She always encourages staff at the centre to do research. Secondly, we would like to express our thanks Dr. Ani Hawkinson for her inspiration and guidance in carrying out class inquiries when she 
was at University of Rwanda and her support in proofreading the paper. Finally, we give thanks to our students in Animal Production and Veterinary Medicine who accepted to take part in the class inquiry.

\section{References}

Abgesi, A.W. (2016). Attending to the Grammatical Errors of Students using Constructive Teaching and Learning Activities. In: Journal of Education and Practice. University of Education Winneba, 23-32.

Alfares, N. (2017). Benefits and Difficulties of Learning in Group Work in EFL Classes in Saudi Arabia. Canadian Center of Science and Education, 10(7), 247-256.

Al-Hoorie, A. H. (2017). Sixty Years of Language Motivation Research: Looking Back and Looking Forward.

Amara, N. (.2015). Errors Correction in Foreign Language Teaching. The Online Journal of New Horizons in Education. Vol.5, Issue 3.

Athanases, S. Z., Wahleithner, J. M., \& Bennett, L. H. (2012). Learning to attend to culturally and linguistically diverse learners through teacher inquiry in teacher education. Teachers College Record, 114(7).

Beerer, K. M. \& , Alec M.Bodzin, A. M. (2003). Promoting Inquiry Bases Science Instruction: The Validation of the Science Teachi Inquiry Rubric. Journal of Elementary Science Education (2003): 39-49.

Bushra, A. \& Hala, H. F. (2016). Students' Preferences and Attitude towards Oral Error Correction Techniques at Yanbu University College, In: English Language Teaching. Canadian Center of Science and Education, 59-66.

Choudhury, S. (2005). Interaction in Second Lnaguage Classroom. BRAC University Journal, 2(1), 77-82 .

Dawson, K. (2007). The Role of Teacher Inquiry in Helping Prospective Teachers Untangle the Complexities of Technology Use in Classrooms. Journal of Computing in Teacher Education, 5-12. Retrieved August 28, 2019 from https://www.learntechlib.org/p/105328/.

Erdoğan, V. (2005). Contribution of Error Analysis to Foreign Language Teaching . Mersin University Journal of the Faculty of Education, 1(2), 261-270.

Fernández, A. D. (2014). Vocabulary learning in collaborative tasks: A comparison of pair and small group work. In: Language Teaching Research. University of Washington, 497- 520

Gladys, J. \& Daphné, S. (2010). Grammar Teaching and Learning in L2: Necessary, but Boring? In: Foreign Language Annals. The American Council on the Teaching of Foreign Languages, 467-494.

Hansen, C. J. \&Wasson, B. (2015). Teacher Inquiry into Student Learning: The TISL Heart Model and Method for Use in Teachers' Professional Development. In: Nordic Journal of Digital Literacy, 24-49.

Hurst, B., Wallace, R., \& Nixon, S. B. (2013). The Impact of Social Interaction on Student Learning. Reading Horizons: A Journal of Literacy and Language Arts, 52(4). Retrieved fromhttps://scholarworks.wmich.edu/reading_horizons/vol52/iss4/5

Jill, T. L. A. (2017). Action research of an error self-correction intervention: Examining the effects on the spelling accuracy behaviors of fifth-grade students identified as at-risk, 146154. (http://dx.doi.org/10.1080/1045988X.2016.122566; 20 October 2018). 
Kasim, U. (2004). Classroom Interaction in the English Department Speaking Class at State University of Malang. JURNAL ILMU PENDIDIKAN, 11(3).

Kasim, U. (2015). Implementation of Group Work in the Classroom. Lingua, 12(1), 97-106.

Khansir, A. A., \& Pakdel, F. (2018). Place of Error Correction in English Language Teaching. In: Educational Process: International Journal, 189-199.

Lasagabaster, D., Doiz, A. (2016) CLIL students' perceptions of their language Learning process: delving into self-perceived improvement and instructional preferences, Language Awareness. In Language Awareness. 1-17.

Leong, L-M, Ahmadi, S.M. (2017). An Analysis of Factors Influencing Learners' English Speaking Skill. International Journal of Research in English Education, 34-40.

Navaz, A., Sama, F. (2017). Teaching Grammar in the English Language Classroom. Proceedings of 7th International Symposium, 7th \& 8th December 2017, (pp. 653-667). SEUSL.

Papangkorna, P. (2015). Students' Attitude And Preference Toward Error Corrections. $7^{\text {th }}$ World Conference on Educational Sciences, (WCES-2015), 05-07 February 2015, Novotel Athens Convention Center, Athens, Greece, 1841-1846. Athens, Greece : Suan Sunandha Rajabhat University.

Rotim, I. (2015). Learners' Attitudes towards Error Correction in EFL writing (Master's thesis). Retrieved from https://urn.nsk.hr/urn:nbn:hr:142:240120

Sasan, B. \& Yahya G. 2012. Academic Writing and Grammatical Accuracy: The Role of back. In: Gist Education and Learning Research Journal. Shahid Beheshti University, 159-176.

Tabaro, C. (2015). Rwanda's motivation to learn and use English as a medium of instruction. International Journal of Humanities and Social Sciences, Vo. 5. No.2. Pp78-85.

Wu, H.-p. (2014). Types and Attributes of English Writing Errors in the EFL Context-A Study of Error Analysis. Journal of Language Teaching and Research, 5(6), 1256-1262.

Yaccob,N.S, Yunus, M. M. (2019). Language Games in Teaching and Learning English Grammar: A Literature Review. Arab World English Journal, 10, 209-217.

Zhu, H. (1982). An Analysis of College Students' Attitudes towards Error Correction in EFL Context. English Language Teaching, 3(4), 127-131. 